\title{
The growth of open access publishing in geochemistry: an update
}

\author{
OLIVIER POURRET ${ }^{1}$, DASAPTA ERWIN IRAWAN ${ }^{2}$, \\ ANDREW HURSTHOUSE ${ }^{3}$ AND PROF. ERIC D VAN \\ HULLEBUSCH, $\mathrm{PHD}^{4}$ \\ ${ }^{1}$ UniLaSalle \\ ${ }^{2}$ Institut Teknologi Bandung \\ ${ }^{3}$ University of the West of Scotland \\ ${ }^{4}$ Université de Paris, Institut de physique du globe de Paris, \\ CNRS
}

Presenting Author: olivier.pourret@unilasalle.fr

Open Access (OA) describes the free, unrestricted access to and re-use of research articles. Recently, a new wave of interest, debate, and practice surrounding OA publishing has emerged. Here, we provide a simple overview of the trends in OA practice in the broad field of geochemistry. We re-examine a list of 56 journals previously worked by Pourret et al. (2020a) and assess whether Article Processing Charges (APCs) and Journal Impact Factors (JIFs) appear to influence publication or not as previously look by Pourret et al. (2020b). More than $40 \%$ of articles in 2018-2019 were published OA, and about $70 \%$ of that portion in fully OA journals. These had a mean APC of US\$ 900 , whereas the remaining were published in hybrid journals with a higher mean APC of more than \$US 1,800. A moderate and positive correlation is found between the number of OA articles published in hybrids journals and their JIF, whereas there is a stronger positive relationship between the number of $\mathrm{OA}$ articles published in fully OA journals and the APC. For OA articles published in hybrid journals, it seems that the proportion of OA articles tends to increase in journals with higher JIF. The rise in OA publishing has potential impacts on the profiles of researchers and tends to devolve costs from organizations to individuals. Until the geochemistry community makes the decision to move away from journal-based evaluation criteria, it is likely that such high costs will continue to impose financial inequities upon research community. However, geochemists could more widely choose legal self-archiving as an equitable and sustainable way to disseminate their research.

References

Pourret, O., Hursthouse, A., Irawan, D.E., Johannesson, K., Liu, H., Poujol, M., Tartese, R., van Hullebusch, E.D., Wiche, O., 2020a. Open Access publishing practice in geochemistry: overview of current state and look to the future. Heliyon, 6(3).

Pourret, O., Irawan, D.E., Tennant, J.P., Hursthouse, A., van Hullebusch, E.D., 2020b. The growth of open access publishing in geochemistry. Results in Geochemistry, 1: 100001. 